\title{
A retrospective analysis of presentation and management outcome of proptosis in a tertiary care centre of North-East, India-a case series
}

\author{
Dr.Kishor K.Satpute ${ }^{1}$,Dr.Y.Chingsuingamba ${ }^{2}$ \\ (Department of Ophthalmology, Regional Institute of medical Sciences, Imphal $)^{1,2}$
}

\begin{abstract}
Proptosis being a common manifestation of wide variety of diseases inside the orbit and it's spaces, a dilemma always exists regarding it's diagnosis and also outcome after surgical or medical management. Twenty two consecutive cases of proptosis of different age groups presenting in a tertiary care centre of northeast India were reviewed, with regard to their mode of presentation and management outcome. Analysis revealed relative distribution of the different causes of proptosis in the age group of 4years to 86 years. It also highlighted management outcomes in different cases.
\end{abstract}

Key Words: Proptosis, Cellulitis, Thyroid eye disease (TED), Pseudotumour, Crouzon syndrome.

\section{Introduction}

Owing to the rich variety of tissues that have the potential to develop a wide spectrum of diseases inside the bony orbital spaces, dilemma in diagnosis of a case of proptosis as an ophthalmologist is justified. Here we present a case series of proptosis from north east region of India in order to provide an overview of the causation of proptosis and to correlate it etiologically with the other studies on proptosis published so far.

\section{Material \& methods:}

This is a retrospective noncomparative analysis of 22 cases who presented with proptosis in eye OPD between dec.2010 to dec.2012. Demographic details, clinical presentation, investigation details and treatment details retrieved and analyzed.

\section{Result:}

22 patients presenting with proptosis in last 2 years between (dec.2010 to dec.2012) with age group varied from 4 years to 86 years. Male $11(50 \%)$, female 11(50\%).In our series the most common etiology was Thyroid eye disease (TED) 7(32\%) and Cellulitis 5( 22.8\%) followed by pseudotumours 4(18.9\%),trauma (retro bulbar hemorrhage) 2( 9\%) Malignant tumors such as Rhabdomyosarcoma1(4.5\%), Burkitt's lymphoma1(4.5\%) ,choroidal melanoma1(4.5\%), and others (Crouzon syndrome) 1(4.5\%) 10.incidence of the thyroid eye disease and pseudo tumor was in common in women than in men, Traumatic proptosis was found in men. In young age proptosis generally presented as an acute onset and Cellulitis was the commonest etiology. Medical management was carried out successfully in majority of cases with systemic antibiotics and systemic steroids depended on the nature of the disease process. Three patients referred for radiotherapy with successful outcome achieved in one patient. One patient with Burkitt's lymphoma was died due to very aggressive nature of the disease. Surgical management deferred due to lack of subspeciality facility in RIMS.

\begin{tabular}{|l|l|l|}
\hline No. & Etiology & $\mathrm{N}(\%)$ \\
\hline 1 & Thyroid Eye disease(TED) & $7(32 \%)$ \\
\hline 2 & Cellulitis & $5(22.8 \%)$ \\
\hline 3 & Pseudotumour & $4(18.9 \%)$ \\
\hline 4 & Trauma (Retro-bulbar hemorrhage) & $2(9 \%)$ \\
\hline 5 & Rhabdomyosarcoma & $1(4.5 \%)$ \\
\hline 6 & Burkitt's lymphoma & $1(4.5 \%)$ \\
\hline 7 & Choroidal melanoma & $1(4.5 \%)$ \\
\hline 8 & Crouzon syndrome & $1(4.5 \%)$ \\
\hline & & \\
\hline
\end{tabular}




\section{Conclusion-}

There exists great disparity in the etiological distribution for various causes of proptosis in different studies. Sometimes opinion differs on radiological and pathological side which creates the diagnostic dilemma in mind. Our series shows thyroid ophthalmopathy as the commonest cause of proptosis and also shows that most orbital disorders presenting as proptosis can be successively managed by medical or surgical management after proper diagnosis within time to avoid further complications. This is similar to the observation in other series of proptosis.

\section{References:}

[1] Mohan H, Gupta AN. Proptosis - a clinical analysis of 141 cases. Indian J Ophthalmol [serial online] 1968[cited 2009 Oct 13];16:91-7.

[2] Rao KP, Rao KV, RaoMR, Rao BS. Clinical study ofproptosis. Indian J Ophthalmol [serial online] 1982[cited 2009 Oct 13];30:48990

[3] Rootman J: Diseases of the orbit.Philadelphia,JBLippincott,1988,1-162.

[4] Demirci H, Shields CL, Shields JA, Honavar SG,Mercado GJ, Tovilla JC. Orbital tumors in the older adult population. Ophthalmology 2002;109:243-8.

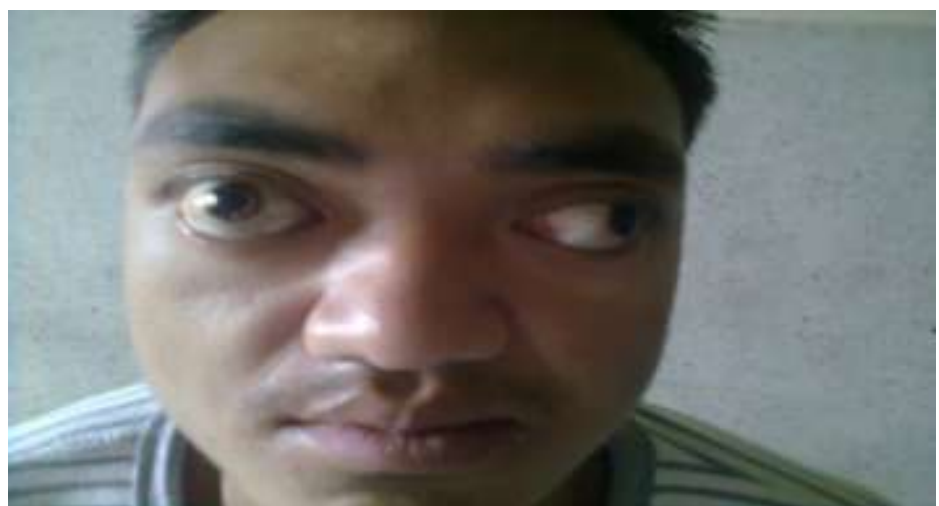

Fig..1. Crouzon syndrome-B/L proptosis

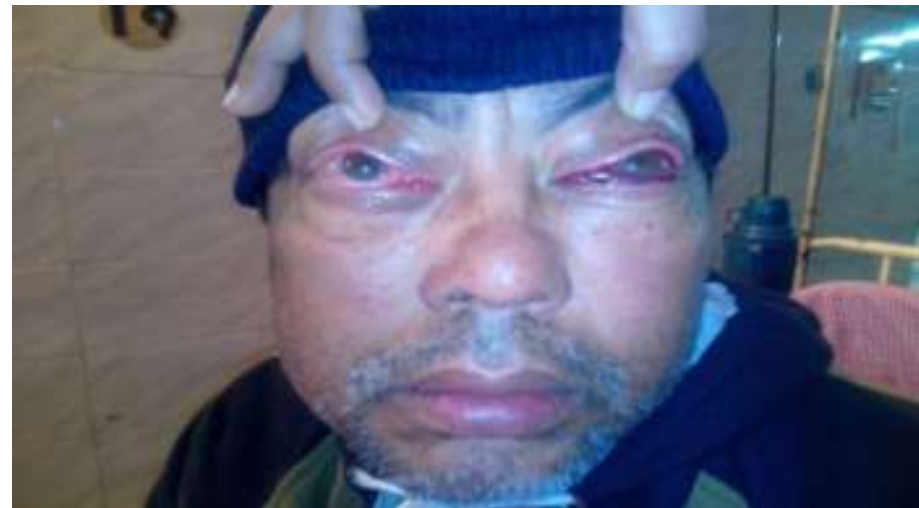

Fig.2-Thyroid Eye Disease(TED)

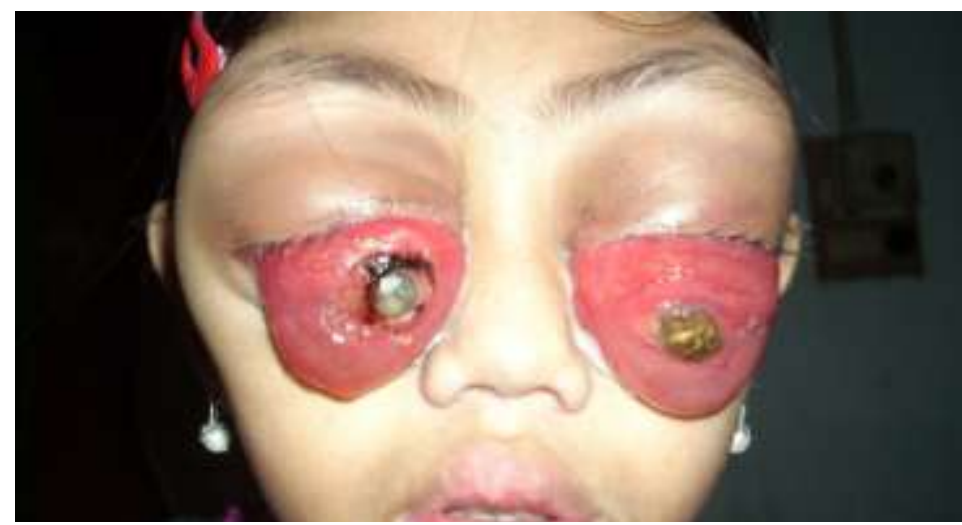

Fig.3.Burkitt's Lymphoma in AIDS patient B/L acute proptosis 


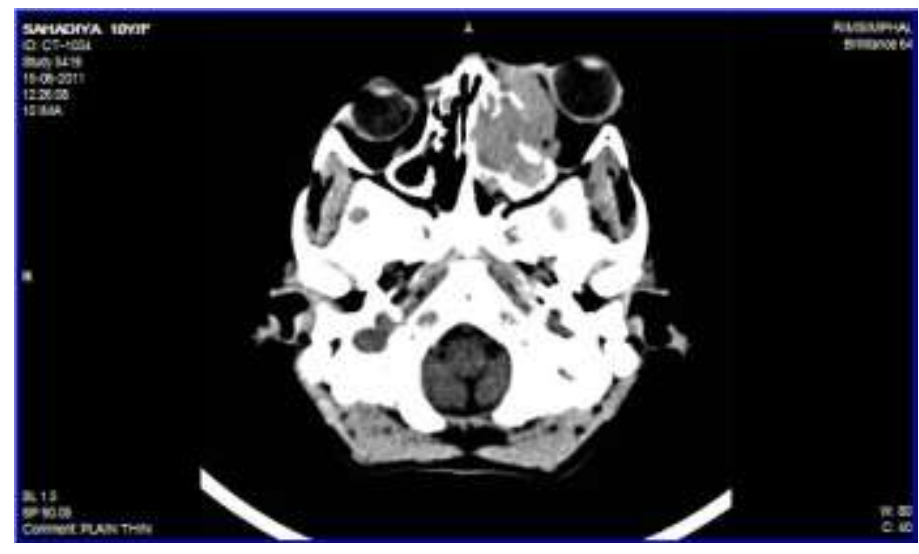

Fig.3b CT Scan orbit axial view-Left orbital Burkitt's lymphoma on initial presentation .

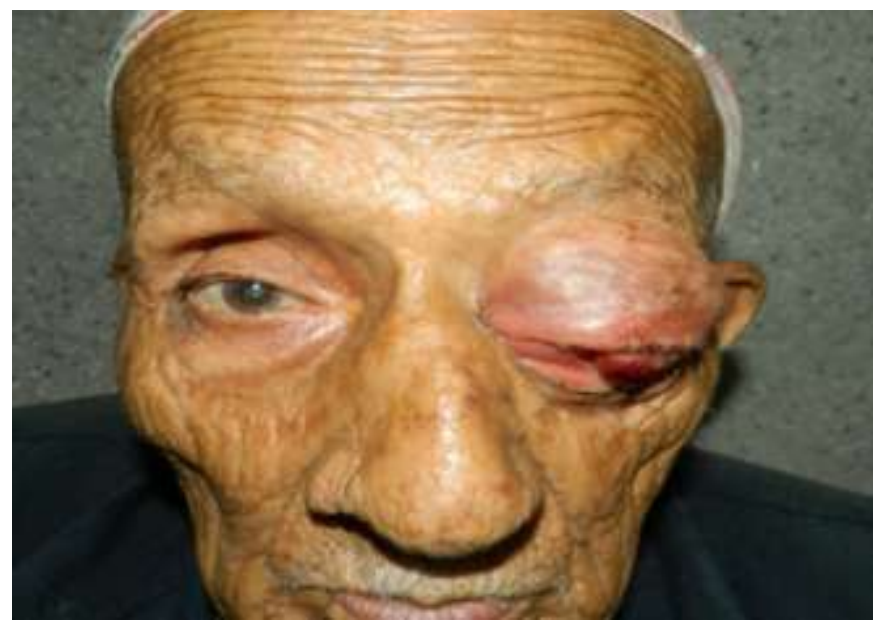

Fig.4 Malignant melanoma of choroid. 